\title{
Analytical Estimation of Water-Oil Relative Permeabilities through Fractures
}

\author{
Hadi Saboorian-Jooybari \\ Reservoir Studies Division, Department of Petroleum Engineering, Main Office Building, \\ National Iranian South Oil Company (NISOC), P.O. Box 61735-1333, Ahvaz - Iran \\ e-mail: hadi.saboorian@gmail.com
}

\begin{abstract}
Modeling multiphase flow through fractures is a key issue for understanding flow mechanism and performance prediction of fractured petroleum reservoirs, geothermal reservoirs, underground aquifers and carbon-dioxide sequestration. One of the most challenging subjects in modeling of fractured petroleum reservoirs is quantifying fluids competition for flow in fracture network (relative permeability curves). Unfortunately, there is no standard technique for experimental measurement of relative permeabilities through fractures and the existing methods are very expensive, time consuming and erroneous. Although, several formulations were presented to calculate fracture relative permeability curves in the form of linear and power functions of flowing fluids saturation, it is still unclear what form of relative permeability curves must be used for proper modeling of flow through fractures and consequently accurate reservoir simulation. Basically, the classic linear relative permeability (X-type) curves are used in almost all of reservoir simulators. In this work, basic fluid flow equations are combined to develop a new simple analytical model for water-oil two phase flow in a single fracture. The model gives rise to simple analytic formulations for fracture relative permeabilities. The model explicitly proves that water-oil relative permeabilities in fracture network are functions of fluids saturation, viscosity ratio, fluids density, inclination of fracture plane from horizon, pressure gradient along fracture and rock matrix wettability, however they were considered to be only functions of saturations in the classic X-type and power (Corey [35] and Honarpour et al. [28, 29]) models. Eventually, validity of the proposed formulations is checked against literature experimental data. The proposed fracture relative permeability functions have several advantages over the existing ones. Firstly, they are explicit functions of the parameters which are known for each of simulation computational cells or easy to measure in laboratory. It is also the first model that takes gravity effects and wettability of fracture walls into consideration and individually developed for water and oil-wet systems. Furthermore, the newly developed formulations are simple, efficient and accurate. Thus, they are recommended for implementation in dual and multiple continuum commercial reservoir simulators.
\end{abstract}

Résumé - Estimation analytique des perméabilités relatives de l'eau et de l'huile d'un réseau de fractures - La modélisation de l'écoulement multiphasique à travers des fractures est un sujet-clé pour mieux modéliser les écoulements au sein des réservoirs pétroliers/géothermiques, des aquifères souterrains ou lors de la séquestration de dioxyde de carbone. Cette étape est essentielle pour évaluer la production d'un réservoir, la capacité de stockage ou prédire les productions futures. Un des sujets les plus difficiles dans la modélisation des réservoirs pétroliers fracturés est de quantifier l'interaction de différents fluides lorsqu'ils s'écoulent dans le réseau de fractures (courbes de la perméabilité relative). Malheureusement, il n'existe pas de technique expérimentale standard pour mesurer la perméabilité relative à travers des fractures et les méthodes existantes sont trop coûteuses, 
chronophages et incertaines. Toutefois, plusieurs formulations ont déjà été proposées pour calculer les courbes de perméabilité relative rendant compte de l'écoulement de fluides dans des fractures. Ces formulations sont des fonctions linéaires ou puissances de saturation des fluides. Cependant, la forme des courbes de perméabilité relative permettant de modéliser correctement l'écoulement à travers des fractures et par conséquent de simuler précisément le réservoir reste sujet à débat. En fait, les courbes classiques de perméabilité relative (type-X) sont utilisées dans presque tous les simulateurs de réservoir. Dans cette étude, les équations de l'écoulement des fluides sont combinées afin de développer un modèle simple et analytique pour le cas de l'écoulement diphasique eau/huile dans une seule fracture. Ce modèle fournit une formulation simple et analytique des perméabilités relatives de fractures. Ce modèle prouve explicitement que les perméabilités relatives eau/huile dans un réseau fracturé sont fonctions de la saturation des fluides, du rapport de viscosité, des densités des fluides, de l'inclination des fractures, du gradient de pression et de la mouillabilité de matrice (roche saine). Il est intéressant de noter que dans les précédents modèles, de type-X ou puissance (Corey [35] and Honarpour et al. [28, 29]), seule une dépendance aux saturations était considérée. Finalement, la validité des formulations proposées est vérifiée par comparaisons à des données expérimentales fournies dans la littérature. Les fonctions de perméabilité relative proposées offrent plusieurs avantages par rapport des celles déjà existantes. Premièrement, elles sont des fonctions explicites de paramètres qui sont soit connus pour chacune des cellules de simulation, ou soit simples à mesurer en laboratoire. Ce modèle est aussi le premier à considérer les effets gravitationnels et une mouillabilité variable de fracture et il a été mis au point pour des systèmes eau/huile. De plus, ces nouvelles formulations développées sont simples, efficaces et précises. Leurs utilisations sont donc recommandées dans les simulateurs de réservoirs commerciaux double ou multiples continuum.

\section{NOMENCLATURE}

A Cross-sectional area to flow (m)

$b \quad$ Fracture aperture $(\mathrm{m})$

$b_{\mathrm{o}} \quad$ Mean value of fracture half-aperture $(\mathrm{m})$

$c_{1}, c_{2} \quad$ Constant of integration

$g \quad$ Acceleration of gravity $\left(9.81 \mathrm{~m} / \mathrm{s}^{2}\right)$

$h \quad$ Height, thickness (m)

$H_{D} \quad$ Ratio of gravity to capillary force (dimensionless)

$k \quad$ Absolute permeability $\left(\mathrm{m}^{2}\right)$

$k_{r} \quad$ Relative permeability (fraction)

$k_{r}{ }^{*} \quad$ End-point relative permeability (fraction)

$n \quad$ Exponent

$P \quad$ Pressure $(\mathrm{Pa})$

$q \quad$ Volumetric flow rate $\left(\mathrm{cm}^{3} / \mathrm{s}\right)$

$S \quad$ Saturation (fraction)

$u \quad$ Velocity $(\mathrm{m} / \mathrm{s})$

$\bar{u} \quad$ Average velocity $(\mathrm{m} / \mathrm{s})$

$W \quad$ Fracture width (m)

\section{GREEK}

$\Delta \quad$ Difference

$\Phi \quad$ Flow potential $(\mathrm{Pa})$

$\begin{array}{ll}\sigma & \text { Interfacial tension }(\mathrm{N} / \mathrm{m}) \\ \mu & \text { Viscosity }(\mathrm{cp}) \\ \tau & \text { Shear stress }(\mathrm{Pa}) \\ \rho & \text { Density }\left(\mathrm{kg} / \mathrm{m}^{3}\right) \\ \gamma & \text { Specific weight }(\mathrm{Pa} / \mathrm{m}) \\ \theta & \text { Inclination degree of fracture plates from horizon, } \\ & \text { contact angle } \\ \partial & \text { Partial differential operator }\end{array}$

\section{SUBSCRIPTS AND SUPERSCRIPTS}

$*$

\section{$c$}

eff

$g$

$i$

l

$m$

$n w$

o

$r$

$w$

$x$

$z$

\author{
Normalized \\ Connate \\ Effective \\ Gas \\ Phase name \\ Liquid \\ Mean (average) \\ Non-wetting phase \\ Oil \\ Residual \\ Water, wetting phase \\ $x$-direction (m) \\ $z$-direction (m)
}




\section{INTRODUCTION}

Naturally fractured reservoirs contain more than $50 \%$ of the known oil and gas reserve worldwide and supply a significant portion of daily oil and gas demands [1]. North Sea chalks, Texas carbonates and Asmari limestone in Iran and Iraq are examples of naturally fractured reservoirs. Despite their significant importance in supplying increasing oil demands, this type of reservoirs exhibits relatively low levels of oil recovery compared to conventional reservoirs. This is mainly attributed to the complex nature of these reservoirs due to presence of two distinct porosity systems (matrix blocks and fractures) that aggravates reservoir heterogeneity and makes reservoir characterization, modeling and simulation a complicated and erroneous task. Furthermore, the oil-wetness tendency of rocks is another cause of very low recovery efficiency in such reservoirs [2]. Multiphase flow in fractured formations is of particular importance for understanding the performance of groundwater hydrology, geothermal reservoirs and disposal of hazardous wastes into underground water. Hydrocarbon reservoirs produce fluids under a combination of mechanisms including capillary, gravity and viscous displacement as well as pore compaction and fluids expansion. The displacement process in a fractured reservoir takes place when gas or water moves rapidly in high permeable fractures and surrounds oil saturated matrix blocks partially or totally. On the other hand, invasion of matrix blocks by gas or water and expulsion of oil into the fracture network begins by the combination of capillary and gravity forces once the matrix block is besieged. This process is called imbibition when the displacing fluid is water, and gravity drainage when the displacing fluid is water. Depending on the flowing phases present in the fractured reservoir, either the capillary or the gravity force becomes dominant [3]. These forces can work in tandem or can oppose each other [4].

A number of researches [5-12] were conducted to shed additional light on production mechanisms of the fractured reservoirs. Reservoir simulation is the most effective and practical method for studying multiphase flow problems in heterogeneous porous media. Numerical modeling of fractured reservoirs can be conducted with several existing techniques [13-18]:

1) dual porosity,

2) dual permeability,

3) Multiple INteracting Continua (MINC),

4) subdomain,

5) Discrete Fracture Network (DFN).

The first four are referred to as multiple continuum techniques in which the reservoir is discretized into a series of high storage capacity matrix blocks and high permeability fracture systems. These approaches have very little differences with each other. In dual porosity models, fluid flow only takes place through fracture systems and matrix blocks act as source and sink. In dual porosity models, matrix blocks are assumed to be connected to each other only through a fracture network, whereas in dual permeability concept the communication can occur between the adjacent blocks, as well as within the fractures. Dual permeability models allow the wells to be completed in both matrix blocks and fractures, but all flow to the wells in dual porosity models takes place through fractures. MINC models generate secondary nested gridding of the matrix blocks based on the initial estimated solution. The subdomain allows user to refine matrix blocks in vertical direction for increasing the accuracy of calculations. The DFN approach generates the model of reservoir spatial distribution of fracture network and detailed knowledge of the fracture intrinsic properties. Although DFN is a very rigorous technique for modeling naturally fractured reservoirs, its application is limited due to lack of the detailed input data required. Therefore, multiple continuum techniques are the most frequently used methods for simulation of fractured porous media. In all of multiple continuum approaches including dual porosity models, the basic governing fluid flow equations are written separately for matrix blocks and fracture systems and then coupled together. Therefore, simulation of fractured reservoirs requires separate sets of relative permeability curves for the two comprising media [19-22].

Rock matrix relative permeabilities are easily measured using a standard experimental procedure on representative plug samples during Special Core Analysis (SCAL). Two techniques are commonly used in the industry for measurements of relative permeabilities: steady-state and unsteadystate methods. In the steady-state technique, two fluids are simultaneously injected at a fixed ratio until saturation and pressure equilibriums are established. Relative permeabilities are directly calculated from the pressure drop and flow rate data. Then, the fluids ratio is adjusted to obtain the relative permeabilities at other saturations. In the unsteady state method, the core plug is saturated with one fluid and the other fluid is injected into the sample either at constant rate or constant pressure while measuring the rate, pressure drop and the volume of the produced fluids. Relative permeabilities are then determined by one of the proposed mathematical methods [23-27]. Detailed descriptions of the experimental procedures of such measurements, mathematical calculation, their advantages and drawbacks and existing empirical correlations can be found in a number of works $[28,29]$. Unfortunately, there is no standard technique for experimental measurement of relative permeabilities through fractures. Furthermore, the existing methods are very expensive, time consuming and sometimes fail to measure fracture properties correctly. For these reasons, development of analytical formulations for relative permeabilities through fractures is of great importance. Although, several 
formulations are presented to calculate fracture relative permeabilities in the form of linear and power functions of saturation, it is still unclear what form of relative permeability curves must be used for proper modeling of multiphase flow through fractures and consequently for accurate reservoir simulation. Upon this review, the necessity of the analytical development of relative permeability functions for fluid flow through fracture network is revealed.

\section{LITERATURE REVIEW}

The ability of a medium to conduct a single phase fluid is known as absolute permeability of that medium. A number of researchers [30-34] have studied absolute permeability of fractures with parallel planar plates and all have reached to the following expression for absolute permeability in single phase, isothermal, laminar and steady-state flow:

$$
k=\frac{b^{2}}{12}
$$

where $b$ is the fracture aperture. In petroleum reservoirs, however, the rock pore spaces are usually occupied by two (or more) phases. In these cases, pores occupied by one phase are unavailable for flow by other phases and the concept of relative permeability is used to describe the competency of phases for flow:

$$
k_{r i}=\frac{k_{e f f, i}}{k}
$$

In this relation, $k_{r i}$ is the relative permeability to phase $i, k$ is the absolute permeability of the porous medium and $k_{\text {eff }, i}$ is the effective permeability to phase $i$. When two or more fluids flow at the same time, the relative permeability is the measure of the conductance of the medium to each fluid phase. Indeed, the effective permeability of each fluid is the permeability of the porous medium to the fluid when the saturation of that fluid is less than $100 \%$ and the relative permeability of the fluid is the ratio of the effective permeability at a specific saturation of the fluid to the absolute permeability of the medium. On the other hand, when a medium is completely saturated with phase $i$, the effective and relative permeabilities of the phase are, respectively, equal to the absolute permeability of the medium and unity $\left(k_{\text {eff }, i}=k\right.$ and $\left.k_{r i}=1\right)$. For the phase $i$ (considering immiscible flow), the generalized Darcy's law can be used to describe flow rates as:

$$
q_{i}=-\frac{A k k_{r i}}{\mu_{i}} \cdot \frac{d \Phi_{i}}{d x}
$$

where $q_{i}$ is the volumetric flow rate of the phase, $A$ is the cross-sectional area to flow, $k$ is the absolute permeability, $k_{r i}$ is the effective permeability, $\mu_{i}$ is viscosity of phase $i$, $\Phi_{i}$ is flow potential of phase $i$ and $x$ is direction of flow.

Since relative permeabilities are strongly saturation dependent, they are crucial to the modeling of multiphase flow in matrix blocks and fracture systems. Despite the importance, there is no consensus on experimental measurement and theoretical calculation of relative permeabilities through fractures. A few data can be found in literature for two phase flow in fractures. The earliest and simplest model was originated in experimental work of Romm [35]. He performed the experiment with water and kerosene through an artificial glass parallel-plate fracture with waxed surfaces. He found a linear relationship between relative permeability and saturation ( $X$-curves), $k_{r i}=S_{i}$ with endpoints at 0 and 1 . Since, in two phase flow:

$$
S_{w}+S_{n w}=1
$$

This will lead to unity value for the summation of the relative permeabilities (Fig. 1):

$$
k_{r, w}+k_{r, n w}=1
$$

where $w$ and $n w$ refer to wetting and non-wetting phases, respectively. This is equivalent to negligible phase interference at all saturations and is the most widely used model in commercial reservoir simulators for numerical modeling of fractured reservoirs. A lot of researchers in petroleum industry [36-39] took Romm's linear relative permeability curves in their works. After Romm [35], Grant [40] and Pruess et al. [41] concluded that the application of $X$-curve for relative permeabilities through fractures is valid in systems with significant phase changes such as steam-water system in geothermal reservoirs.

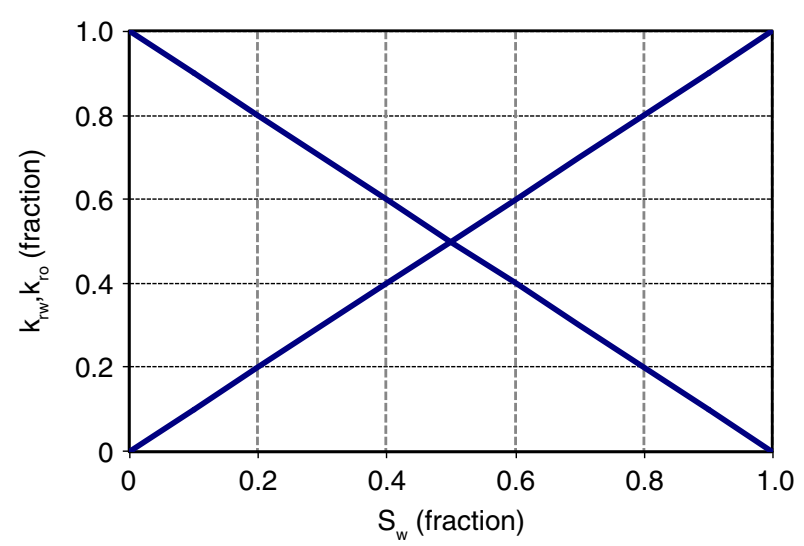

Figure 1

Romm's linear ( $X$-type) relative permeability curves. 
Among limited experimentally measured data available in the literature only a few works observed Romm's $X$-type model for relative permeabilities in fractures. Indeed, most of the data indicate considerable departure from straight line behavior. Romm's experiment with water and oil was duplicated by Merrill [42] in glass parallel-plates fracture and in natural porous media split along the length by sawing without using waxed paper strips as spacers. Since most of the data in his experiments scattered over a narrow range of water saturation (around a value of $71 \%$ ), attempts failed to correlate relative permeability with saturation. However, the limited data indicated considerable deviation from the $X$-curve. A number of other analytical [43] and numerical [44] works for two phase flow in rough-walled and variable aperture fractures showed existence of considerable interference between phases and consequently $k_{r, w}+k_{r, n w}<<1$. Apart from oil-water system, other researchers [45-48] conducted experiments with air and water and observed failure of the $X$-curve to model fracture relative permeabilities.

A number of experimental studies found that two phase flow in fractures is better described using straight line relative permeabilities with slope less than one. Pan et al. [49] suggested that the slope of 0.6 for air and 0.7 for water relative permeability functions give rise to better match to experimental data. While, Rangel-German et al. [50] obtained the slope of 0.6 for both air and water relative permeabilities. Replacement of the unity slope of the $X$-curve model by smaller slopes in these works is an indication of occurrence of higher flow resistance in fractures because of strong interference between the flowing phases.

Some researchers [51-54] concluded that experimentally measured relative permeability curves are better matched with porous media approach (Corey model [55]) as:

$$
\begin{gathered}
k_{r, l}=S^{* 4} \\
k_{r, g}=\left(1-S^{* 2}\right)\left(1-S^{*}\right)^{2}
\end{gathered}
$$

where $S^{*}$ is normalized liquid saturation defined as:

$$
S^{*}=\frac{S_{l}-S_{l r}}{1-S_{l r}-S_{g r}}
$$

and $S_{g}$ and $S_{l}$ are gas and liquid saturations, respectively. Meanwhile, the subscript $r$ refers to residual saturations of the phases. In contrary to the above works, experimental studies of Persoff et al. [45] and Persoff and Pruess [46] concluded that fracture relative permeability cannot be well fitted neither by straight-line nor by Corey model.

The other model known as pipe flow model treated flow through fractures as flow through a system of pipes to construct fracture relative permeability curves [47, 48]. In this approach, a phase can be carried by the other phase as bubbles, mist, slug and other structures without need of establishing a continuous flow path. The models that were developed on the basis of pipe flow approach can be categorized in two classes:

- viscous coupling,

- equivalent homogeneous single-phase models.

The viscous coupling model was firstly introduced by Fourar et al. [56] for the simple case of lubricated film flow in a pipe equivalent to fracture as:

$$
k_{r, l}=\frac{S_{l}^{2}}{2}\left(3-S_{l}\right)
$$

and

$$
k_{r, g}=\left(1-S_{l}\right)^{3}+\frac{3}{2} \cdot \frac{\mu_{g}}{\mu_{l}} \cdot S_{l}\left(1-S_{l}\right)\left(2-S_{l}\right)
$$

In 2010, Shad and Gates [57] extended the viscous coupling model to more than one phase systems. In another pipe flow model, which is known as equivalent homogeneous singlephase model, Fourar et al. [47] considered the two phase flow to be equivalent to single phase flow of a homogenous phase through a system of pipes. The average density and viscosity of the equivalent homogenous phase are calculated by weighting properties of each phases by the corresponding volumetric flow rates as:

$$
\begin{gathered}
\rho_{m}=\frac{\rho_{1} q_{1}+\rho_{2} q_{2}}{q_{1}+q_{2}} \\
\mu_{m}=\frac{\mu_{1} q_{1}+\mu_{2} q_{2}}{q_{1}+q_{2}}
\end{gathered}
$$

where the subscript $m$ refers to average value.

As it was here mentioned above, despite its essential importance, only a few experimental, numerical and analytical attempts have been made to clear the physics of multiphase flow and characteristic of relative permeabilities in fractures. Therefore, the extremely important question of proper form of relative permeability curves through fractures is still unanswered. This paper is an attempt to develop a new simple analytical model for description of characteristic behavior of water-oil relative permeabilities in fractures.

\section{MATHEMATICAL FORMULATION}

In two phase flow of immiscible fluids, the wetting-phase flows along the fracture wall and the non-wetting phase occupies the fracture interior $[58,59]$. The potential gradient 


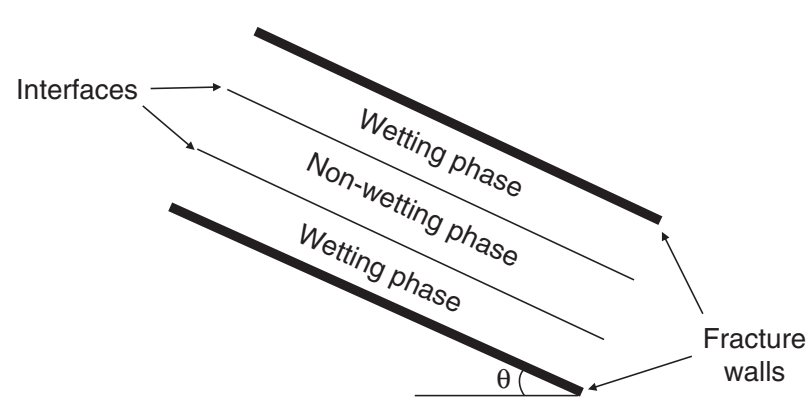

Figure 2

Illustration of wetting and non-wetting phase flow along the wall and interior of a fracture.

along fracture determines the thickness of each phase (Fig. 2). Water-oil two phase flow between the parallel fracture plates are considered to be laminar, incompressible and steady state. An infinitesimal thin lamina is taken as a control volume (free body) to analyze the flow (Fig. 3). Linear momentum of the element of a mass $d m$ is a vector defined as $d m \boldsymbol{V}$. In this case, the mass $d m$ is a part of velocity field:

$$
\boldsymbol{V}=u \boldsymbol{i}+v \boldsymbol{j}+w \boldsymbol{k}
$$

The fundamental statement of the second law of Newton in terms of linear momentum of the element is given as:

$$
d \boldsymbol{F}_{\text {ext }}=\frac{D}{D t}(d m \boldsymbol{V})
$$

where $D$ is the essential derivative defined as:

$$
\frac{D}{D t}=\frac{\partial}{\partial t}+u \frac{\partial}{\partial x}+v \frac{\partial}{\partial y}+w \frac{\partial}{\partial z}
$$

and $\boldsymbol{F}_{\boldsymbol{e x t}}$ is the external forces acting over the control volume. These forces can be classified as the body and surface forces. In absence of a magnetic/electric field, gravity is the only body force which can be expressed as $-\rho g d v \nabla h$. The surface forces on the particle are due to pressure and shear stress respectively in the form of $-d v \nabla P$ and $-d v \nabla \tau$. The shearing stress $(\tau)$ is the force that acts on the unit area of interface between the particles tangent to the direction of flow. As we know, substituting these forces in Equation (14) and dividing through by $d v$ leads to the very famous Navier-Stokes equation:

$$
\rho\left(\frac{\partial \boldsymbol{V}}{\partial t}+(\boldsymbol{V} \cdot \boldsymbol{\nabla}) \boldsymbol{V}\right)=-\rho g \boldsymbol{\nabla} h-\nabla P-\nabla \tau
$$

where $h$ is the vertical direction. Since for the laminar, incompressible and steady state condition shown in Figure 3,

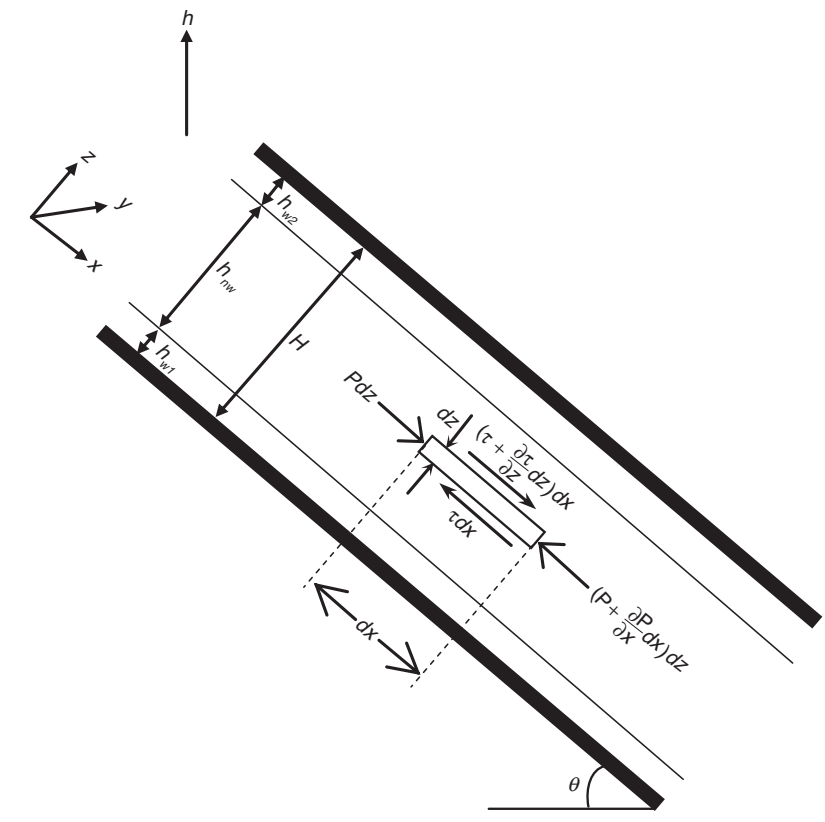

Figure 3

Momentum balance for two phase immiscible flow in an inclined fracture.

for flow in the $x$ direction, we have $v=w=0$. Thus, the only nonzero stress from $\tau_{i j}$ is $\tau_{x z}$. With these in mind, the vector Equation (16) reduces to the following scalar equation of motion in the $x, y$ and $z$ directions:

$$
\begin{gathered}
\frac{\partial \tau_{x z}}{\partial z}=\frac{\partial P}{\partial x}+\rho g \frac{\partial h}{\partial x} \\
\frac{\partial P}{\partial y}=-\rho g \cos (\theta) \\
\frac{\partial P}{\partial z}=0
\end{gathered}
$$

where $\theta$ is the inclination degree of the fracture from the horizontal line. The equations obtained in the $y$ and $z$ directions are trivial. Thus, Equation (17) is the only equation that should be employed for the further analysis as:

$$
\frac{\partial \tau_{x z}}{\partial z}=\frac{\partial(P+\rho g h)}{\partial x}
$$

Since the only nonzero component of the stress field is $\tau_{x z}$, the subscript $x z$ will be omitted hereafter for simplicity. 
As we know, $P+\rho g h$ is called flow potential. Therefore, Equation (20) can be rewritten as:

$$
\frac{\partial \tau}{\partial z}=\frac{\partial \Phi}{\partial x}
$$

Since $\tau$ and $\Phi$ are only functions of $z$ and $x$, respectively:

$$
\frac{d \tau}{d z}=\frac{d \Phi}{d x}
$$

Integration of this equation with respect to $z$ gives:

$$
\tau=\frac{d \Phi}{d x} \cdot z+c_{1}
$$

This equation is valid for the three streams in Figure 2:

$$
\begin{gathered}
\tau_{w_{1}}=\frac{d \Phi_{w_{1}}}{d x} \cdot z+c_{1}^{w_{1}} \\
\tau_{n w}=\frac{d \Phi_{n w}}{d x} \cdot z+c_{1}^{n w} \\
\tau_{w_{2}}=\frac{d \Phi_{w_{2}}}{d x} \cdot z+c_{1}^{w_{2}}
\end{gathered}
$$

In which $c_{1}^{w_{1}}, c_{1}^{n w}$ and $c_{1}^{w_{2}}$ are constants of integration. In order to make the formulations simpler, thickness of the two regions of wetting phase at the top and bottom walls of the fracture is assumed to be equal $\left(h_{w_{1}}=h_{w_{2}}=h_{w}\right)$. Because of symmetry of the system in Figure 3:

$$
\frac{d \Phi_{w_{1}}}{d x}=\frac{d \Phi_{w_{2}}}{d x}=\frac{d \Phi_{w}}{d x}
$$

And flow potential gradient of the wetting and non-wetting phases are related as:

$$
\frac{d \Phi_{n w}}{d x}=\frac{d \Phi_{w}}{d x}+\left(\rho_{w}-\rho_{n w}\right) g \sin (\theta)
$$

To evaluate Equations (24) through (26), the continuity of fluid mechanics properties at interface between three flow regions in Figures 2 and 3 necessitates:

$$
\begin{gathered}
z=0, \tau_{w_{1}}=\tau_{n w} \\
z=h_{n w}, \tau_{n w}=\tau_{w_{2}}
\end{gathered}
$$

Substituting these boundary conditions in Equations (24) through (26) yields:

$$
c_{1}^{w_{1}}=c_{1}^{n w}=c_{1}^{w_{2}}=c_{1}
$$

Equations (24) through (26) can be combined with Newton's law of viscosity to get the following equations, respectively:

$$
\mu_{w} \frac{d u_{w_{1}}}{d z}=\frac{d \Phi_{w}}{d x} \cdot z+c_{1}
$$

$$
\mu_{n w} \frac{d u_{n w}}{d z}=\frac{d \Phi_{n w}}{d x} \cdot z+c_{1}
$$

$$
\mu_{w} \frac{d u_{w_{2}}}{d z}=\frac{d \Phi_{w}}{d x} \cdot z+c_{1}
$$

Integration of these equations with respect to $z$ leads to velocity profiles in the three flow regions as follows:

$$
\begin{aligned}
& u_{w_{1}}=\frac{1}{\mu_{w}}\left[\frac{d \Phi_{w}}{d x} \cdot \frac{z^{2}}{2}+c_{1} \cdot z\right]+c_{2}^{w_{1}} \\
& u_{n w}=\frac{1}{\mu_{n w}}\left[\frac{d \Phi_{n w}}{d x} \cdot \frac{z^{2}}{2}+c_{1} \cdot z\right]+c_{2}^{n w} \\
& u_{w_{2}}=\frac{1}{\mu_{w}}\left[\frac{d \Phi_{w}}{d x} \cdot \frac{z^{2}}{2}+c_{1} \cdot z\right]+c_{2}^{w_{2}}
\end{aligned}
$$

Determination of the integration constants $\left(c_{1}, c_{2}^{w_{1}}, c_{2}^{n w}\right.$ and $c_{2}^{w_{2}}$ ) needs the following boundary conditions (Streeter et al. [60]):

$$
z=-h_{w}, u_{w_{1}}=0
$$

$$
\begin{gathered}
z=0, u_{w_{1}}=u_{n w} \\
z=h_{n w}, u_{n w}=u_{w_{2}} \\
z=h_{n w}+h_{w}, u_{w_{2}}=0
\end{gathered}
$$

Substitution of the boundary conditions in Equations (35) through (37) yields:

$$
c_{2}^{w_{1}}=-\frac{1}{\mu_{w}}\left[\frac{d \Phi_{w}}{d x} \cdot \frac{h_{w}^{2}}{2}-c_{1} \cdot h_{w}\right]
$$

$$
c_{2}^{w_{1}}=c_{2}^{n w}
$$




$$
\begin{aligned}
c_{2}^{w_{2}}= & c_{2}^{n w}+\frac{1}{\mu_{n w}}\left[\frac{d \Phi_{n w}}{d x} \cdot \frac{h_{n w}^{2}}{2}+c_{1} \cdot h_{n w}\right] \\
& -\frac{1}{\mu_{w}}\left[\frac{d \Phi_{w}}{d x} \cdot \frac{h_{n w}^{2}}{2}+c_{1} \cdot h_{n w}\right] \\
c_{2}^{w_{2}}= & -\frac{1}{\mu_{w}}\left[\frac{d \Phi_{w}}{d x} \cdot \frac{\left(h_{n w}+h_{w}\right)^{2}}{2}+c_{1} \cdot\left(h_{n w}+h_{w}\right)\right]
\end{aligned}
$$

Solving the system of four equations (Eqs. 42 through 45) and four unknowns $\left(c_{1}, c_{2}^{w_{1}}, c_{2}^{n w}\right.$ and $\left.c_{2}^{w_{2}}\right)$ results in the following solutions:

$$
\begin{aligned}
& c_{1}=-\frac{\frac{h_{w} h_{n w}}{\mu_{w}} \cdot \frac{d \Phi_{w}}{d x}+\frac{h_{n w}^{2}}{2 \mu_{n w}} \cdot \frac{d \Phi_{n w}}{d x}}{\frac{2 h_{w}}{\mu_{w}}+\frac{h_{n w}}{\mu_{n w}}} \\
& c_{2}^{w_{1}}=c_{2}^{n w}=-\frac{1}{\mu_{w}} \\
& \times\left[\frac{h_{w}^{2}}{2} \cdot \frac{d \Phi_{w}}{d x}+\frac{\frac{h_{w}^{2} h_{n w}}{\mu_{w}} \cdot \frac{d \Phi_{w}}{d x}+\frac{h_{n w}^{2} h_{w}}{2 \mu_{n w}} \cdot \frac{d \Phi_{n w}}{d x}}{\frac{2 h_{w}}{\mu_{w}}+\frac{h_{n w}}{\mu_{n w}}}\right] \\
& c_{2}^{w_{2}}=-\frac{1}{\mu_{w}} \cdot\left[\frac{\left(h_{w}+h_{n w}\right)^{2}}{2} \cdot \frac{d \Phi_{w}}{d x}\right. \\
& \left.-\left(h_{w}+h_{n w}\right) \frac{\frac{h_{w} h_{n w}}{\mu_{w}} \cdot \frac{d \Phi_{w}}{d x}+\frac{h_{n w}^{2}}{2 \mu_{n w}} \cdot \frac{d \Phi_{n w}}{d x}}{\frac{2 h_{w}}{\mu_{w}}+\frac{h_{n w}}{\mu_{n w}}}\right]
\end{aligned}
$$

Substituting the integration constants in Equations (35) to (37) yields the velocity profiles in the three flow regions. Knowing the velocity profiles, it is simple to calculate average velocity for each of the flowing streams:

$$
\begin{aligned}
& \overline{u_{w_{1}}}=\frac{\int_{-h_{w}}^{0} u_{w} d z}{\int_{-h_{w}}^{0} d z}=\frac{1}{\mu_{w}}\left[\frac{d \Phi_{w}}{d x} \cdot \frac{h_{w}^{2}}{6}-c_{1} \cdot \frac{h_{w}}{2}\right]+c_{2}^{w_{1}} \\
& \overline{u_{n w}}=\frac{\int_{0}^{h_{n w}} u_{w} d z}{\int_{0}^{h_{n w}} d z}=\frac{1}{\mu_{n w}}\left[\frac{d \Phi_{n w}}{d x} \cdot \frac{h_{n w}^{2}}{6}+c_{1} \cdot \frac{h_{n w}}{2}\right]+c_{2}^{n w}
\end{aligned}
$$

$$
\begin{aligned}
\overline{u_{w_{2}}}= & \frac{\int_{h_{n w}}^{h_{n w}+h_{w}} u_{w_{2}} d z}{\int_{h_{n w}}^{h_{n w}+h_{w}} d z} \\
= & \frac{1}{\mu_{w} h_{w}}\left[\frac{d \Phi_{w}}{d x} \cdot\left(\frac{\left(h_{n w}+h_{w}\right)^{3}}{6}-\frac{h_{n w}^{3}}{6}\right)\right. \\
& \left.+c_{1} \cdot\left(\frac{\left(h_{n w}+h_{w}\right)^{2}}{2}-\frac{h_{n w}^{2}}{2}\right)\right]+c_{2}^{w_{2}} h_{w}
\end{aligned}
$$

Substitution of the integration constants in above equations we obtain:

$$
\begin{aligned}
\overline{u_{w_{1}}}= & \frac{\int_{-h_{w}}^{0} u_{w} d z}{\int_{-h_{w}}^{0} d z}=-\frac{1}{\mu_{w}} \cdot \frac{d \Phi_{w}}{d x} \cdot\left(\frac{h_{w}^{2}}{3}+\frac{h_{w} h_{n w}}{4}\right) \\
& -\frac{h_{w} h_{n w}^{2}\left(\rho_{w}-\rho_{n w}\right) g \sin (\theta)}{4 \mu_{w} \mu_{n w}\left(\frac{2 h_{w}}{\mu_{w}}+\frac{h_{n w}}{\mu_{n w}}\right)} \\
\overline{u_{n w}}= & \frac{\int_{0}^{h_{n w}} u_{w} d z}{\int_{0}^{h_{n w}} d z}=-\frac{1}{2} \cdot \frac{d \Phi_{n w}}{d x} \cdot\left(\frac{h_{n w}^{2}}{6 \mu_{n w}}+\frac{h_{w}^{2}+h_{w} h_{n w}}{\mu_{w}}\right) \\
& +\frac{h_{w}}{2 \mu_{w}}\left(h_{w}+h_{n w}\right)\left(\rho_{w}-\rho_{n w}\right) g \sin (\theta) \\
\overline{u_{w_{2}}}= & \frac{\int_{h_{n w}}^{h_{n w}+h_{w}} u_{w_{2}} d z}{\int_{h_{n w}}^{h_{n w}+h_{w}} d z}=-\frac{1}{\mu_{w}} \cdot \frac{d \Phi_{w}}{d x} \cdot\left(\frac{h_{w}^{2}}{3}+\frac{h_{w} h_{n w}}{4}\right) \\
& -\frac{h_{w} h_{n w}^{2}\left(\rho_{w}-\rho_{n w}\right) g \sin (\theta)}{4 \mu_{w} \mu_{n w}\left(\frac{2 h_{w}}{\mu_{w}}+\frac{h_{n w}}{\mu_{n w}}\right)}
\end{aligned}
$$

Comparison of Equations (52) and (54) indicates that average velocity of the wetting phase regions are equal to each other. The volumetric flow rate of each of the three regions is the product of average velocity and area of the stream:

$$
\begin{gathered}
q_{w_{1}}=q_{w_{2}}=W h_{w}\left[-\frac{1}{\mu_{w}} \cdot \frac{d \Phi_{w}}{d x} \cdot\left(\frac{h_{w}^{2}}{3}+\frac{h_{w} h_{n w}}{4}\right)\right. \\
-\frac{h_{w} h_{n w}^{2}\left(\rho_{w}-\rho_{n w}\right) g \sin (\theta)}{\left.4 \mu_{w} \mu_{n w}\left(\frac{2 h_{w}}{\mu_{w}}+\frac{h_{n w}}{\mu_{n w}}\right)\right]} \\
q_{n w}=W h_{n w}\left[-\frac{1}{2} \cdot \frac{d \Phi_{n w}}{d x} \cdot\left(\frac{h_{n w}^{2}}{6 \mu_{n w}}+\frac{h_{w}^{2}+h_{w} h_{n w}}{\mu_{w}}\right)\right. \\
\left.+\frac{h_{w}}{2 \mu_{w}}\left(h_{w}+h_{n w}\right)\left(\rho_{w}-\rho_{n w}\right) g \sin (\theta)\right]
\end{gathered}
$$


Therefore, total flow rate of the wetting phase would be:

$$
\begin{aligned}
q_{w}=2 W h_{w} & -\frac{1}{\mu_{w}} \cdot \frac{d \Phi_{w}}{d x} \cdot\left(\frac{h_{w}^{2}}{3}+\frac{h_{w} h_{n w}}{4}\right) \\
& \left.-\frac{h_{w} h_{n w}^{2}\left(\rho_{w}-\rho_{n w}\right) g \sin (\theta)}{4 \mu_{w} \mu_{n w}\left(\frac{2 h_{w}}{\mu_{w}}+\frac{h_{n w}}{\mu_{n w}}\right)}\right]
\end{aligned}
$$

For flow through the fracture, the volumetric flow rate also can be obtained from Darcy's law:

$$
\begin{gathered}
q_{w}=-\frac{k k_{r w} W\left(2 h_{w}+h_{n w}\right)}{\mu_{w}} \cdot \frac{d \Phi_{w}}{d x} \\
q_{n w}=-\frac{k k_{r n w} W\left(2 h_{w}+h_{n w}\right)}{\mu_{n w}} \cdot \frac{d \Phi_{n w}}{d x}
\end{gathered}
$$

where $k$ is absolute permeability of the fracture that is calculated using Equation (1) as:

$$
k=\frac{\left(2 h_{w}+h_{n w}\right)^{2}}{12}
$$

Substituting Equations (58) and (59) in Equations (57) and (56) yields the following expressions for wetting and nonwetting phase relative permeabilities, respectively:

$$
\begin{gathered}
k_{r w}=\frac{24 h_{w}}{\left(2 h_{w}+h_{n w}\right)^{3}} \\
\times\left[\left(\frac{h_{w}^{2}}{3}+\frac{h_{w} h_{n w}}{4}\right)+\frac{h_{w} h_{n w}^{2}\left(\rho_{w}-\rho_{n w}\right) g \sin (\theta)}{\left.4 \mu_{n w}\left(\frac{2 h_{w}}{\mu_{w}}+\frac{h_{n w}}{\mu_{n w}}\right) \frac{d \Phi_{w}}{d x}\right]}\right. \\
k_{r n w}=\frac{12 \mu_{n w} h_{n w}}{\left(2 h_{w}+h_{n w}\right)^{3}}\left[\frac{1}{2}\left(\frac{h_{n w}^{2}}{6 \mu_{n w}}+\frac{h_{w}^{2}+h_{w} h_{n w}}{\mu_{w}}\right)\right. \\
\left.\quad-\frac{h_{w}}{2 \mu_{w}}\left(h_{w}+h_{n w}\right) \frac{\left(\rho_{w}-\rho_{n w}\right) g \sin (\theta)}{\frac{d \Phi_{n w}}{d x}}\right]
\end{gathered}
$$

In order to define relative permeabilities in terms of saturations, wetting and non-wetting phase saturations are defined as:

$$
\begin{gathered}
S_{w}=\frac{2 h_{w}}{2 h_{w}+h_{n w}} \\
S_{n w}=\frac{h_{n w}}{2 h_{w}+h_{n w}}
\end{gathered}
$$

Eventually, simple rearrangement of Equations (61) and (62) followed by substitution of Equations (63) and (64) gives rise to the following analytical expressions to estimate relative permeabilities in an inclined fracture:

$$
\begin{aligned}
k_{r w}=12 S_{w}[ & \left(\frac{S_{w}^{2}}{12}+\frac{S_{w} S_{n w}}{8}\right) \\
& \left.+\frac{S_{n w}^{2}\left(\rho_{w}-\rho_{n w}\right) g \sin (\theta)}{8\left(\frac{1}{\mu_{r}}+\frac{S_{n w}}{S_{w}}\right)\left(\frac{d P}{d x}-\rho_{w} g \sin (\theta)\right)}\right]
\end{aligned}
$$

$$
\begin{aligned}
k_{r n w}=12 S_{n w} & {\left[\frac{1}{2}\left(\frac{S_{n w}^{2}}{6}+\frac{S_{w}^{2}+2 S_{w} S_{n w}}{4 \mu_{r}}\right)\right.} \\
& \left.-\frac{S_{w}}{4 \mu_{r}}\left(\frac{S_{w}}{2}+S_{n w}\right) \frac{\left(\rho_{w}-\rho_{n w}\right) g \sin (\theta)}{\frac{d P}{d x}-\rho_{n w} g \sin (\theta)}\right]
\end{aligned}
$$

where $d P / d x$ is the pressure gradient along the fracture and $\mu_{r}$ is viscosity ratio which is the wetting to non-wetting phase viscosity ratio $\left(\mu_{w} / \mu_{n w}\right)$. The newly developed relative permeability formulas in Equations (65) and (66) are explicit functions of phase saturations, viscosity ratio, fluids density, inclination of fracture from horizon, pressure gradient along fracture and rock matrix wettability. On the other hand, the newly developed relative permeability curves in Equations (65) and (66) are explicit functions of the parameters which are known for each of simulation computational cells or easy to measure in laboratory. Moreover, it is also the first relative permeability model that takes the gravity and wettability effects into account.

\section{EFFECTS OF WETTABILITY AND VISCOSITY RATIO}

\subsection{Fracture Surface Wettability}

In the previous section, general formulations of relative permeability curves were proposed for two-phase flow through fractures. In this section, it is intended to apply them to water-oil systems with strong water- and oil-wetness of the fracture walls and investigate the effects of wettability on the relative permeabilities. In the case of strongly water wet reservoir rock, Equations (65) and (66) take the following forms:

$$
\begin{aligned}
k_{r w}=12 S_{w} & {\left[\left(\frac{S_{w}^{2}}{12}+\frac{S_{w}\left(1-S_{w}\right)}{8}\right)\right.} \\
& \left.+\frac{\left(1-S_{w}\right)^{2}\left(\rho_{w}-\rho_{o}\right) g \sin (\theta)}{8\left(\frac{1}{\mu_{r}}+\frac{1-S_{w}}{S_{w}}\right)\left(\frac{d P}{d x}-\rho_{w} g \sin (\theta)\right)}\right]
\end{aligned}
$$




$$
\begin{aligned}
k_{r o}= & 12\left(1-S_{w}\right)\left[\frac{1}{2}\left(\frac{\left(1-S_{w}\right)^{2}}{6}+\frac{S_{w}^{2}+2 S_{w}\left(1-S_{w}\right)}{4 \mu_{r}}\right)\right. \\
& \left.-\frac{S_{w}}{4 \mu_{r}}\left(1-\frac{S_{w}}{2}\right) \frac{\left(\rho_{w}-\rho_{o}\right) g \sin (\theta)}{\frac{d P}{d x}-\rho_{o} g \sin (\theta)}\right]
\end{aligned}
$$

and for strong oil-wetness of the fracture walls:

$$
\begin{aligned}
k_{r w}= & 12 S_{w}\left[\frac{1}{2}\left(\frac{S_{w}^{2}}{6}+\frac{\left(1-S_{w}\right)^{2}+2 S_{w}\left(1-S_{w}\right)}{4 \mu_{r}}\right)\right. \\
- & \left.\frac{\left(1-S_{w}\right)}{4 \mu_{r}}\left(\frac{1+S_{w}}{2}\right) \frac{\left(\rho_{o}-\rho_{w}\right) g \sin (\theta)}{\frac{d P}{d x}-\rho_{w} g \sin (\theta)}\right] \\
k_{r o}= & 12\left(1-S_{w}\right)\left[\left(\frac{\left(1-S_{w}\right)^{2}}{12}+\frac{S_{w}\left(1-S_{w}\right)}{8}\right)\right. \\
& \left.+\frac{S_{w}^{2}\left(\rho_{o}-\rho_{w}\right) g \sin (\theta)}{8\left(\frac{1}{\mu_{r}}+\frac{S_{w}}{1-S_{w}}\right)\left(\frac{d P}{d x}-\rho_{o} g \sin (\theta)\right)}\right]
\end{aligned}
$$

where the subscripts $w$ and $o$ stand for water and oil phases, respectively. Figure 4 shows a comparison between the relative permeabilities for strongly water and oil-wet fractures using Equations (67) to (70) for the rock and fluids properties of Table 1 . This figure clearly indicates strong dependence of fracture relative permeability curves to the wettability of the walls. The other important point that can be inferred from this figure is that the value of oil relative permeability in the water-wet

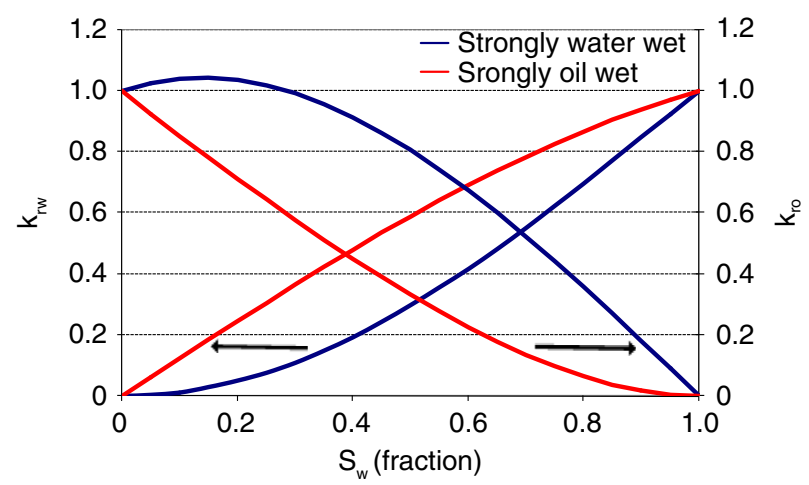

Figure 4

Comparison between relative permeabilities for strongly water and oil wet fractures for the rock and fluids properties of Table $1\left(\mu_{r}=1\right)$. system exceeds unity over a limited range of saturation for the data of Table $1\left(\mu_{r}=1\right)$. The reason for observing such behavior is described in the following section.

Equations (67) through (70) can be used for analytical estimation of oil and water relative permeability curves through an inclined fracture as long as the flowing phases configuration is as depicted in Figures 2 and 3. In two-phase flow of water and heavy oils, the aqueous phase is underridden by the more viscous oleic phase regardless of wettability of the fracture walls (Fig. 5). Following the same procedure as here presented above leads to the following expressions for this kind of stratified flow pattern:

$$
\begin{aligned}
k_{r w}= & \frac{S_{w}^{2}}{S_{w}\left(1-\mu_{r}\right)+\mu_{r}} \\
& \cdot\left[S_{w}^{2}+4 \mu_{r} S_{w}\left(1-S_{w}\right)+3 \mu_{r}\left(1-S_{w}\right)^{2}\right. \\
& \left.\times\left(1+\frac{\left(\rho_{o}-\rho_{w}\right) g \sin (\theta)}{\frac{d P}{d x}-\rho_{w} g \sin (\theta)}\right)\right]
\end{aligned}
$$

TABLE 1

Summary of the rock and fluids properties used to plot Figure 4

\begin{tabular}{c|c}
\hline Parameters & Value \\
\hline Inclination $(\mathrm{deg})$ & 45 \\
\hline$d P / d x(\mathrm{kPa} / \mathrm{m})$ & -2.26 \\
\hline Oil density $\left(\mathrm{kg} / \mathrm{m}^{3}\right)$ & 862 \\
\hline Water density $\left(\mathrm{kg} / \mathrm{m}^{3}\right)$ & 1115 \\
\hline Oil viscosity $(\mathrm{cp})$ & 1.5 \\
\hline Water viscosity $(\mathrm{cp})$ & 1.5 \\
\hline
\end{tabular}

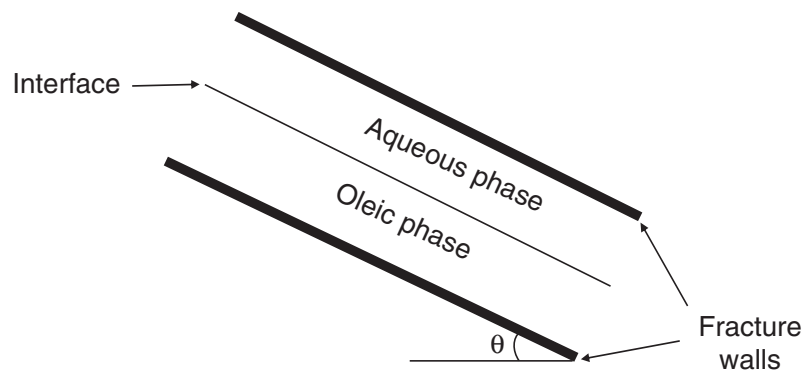

Figure 5

Illustration of wetting and non-wetting phase flow in stratified flow of oil along the bottom and water along the top walls of a fracture. 


$$
\begin{aligned}
k_{r o}= & \frac{\left(1-S_{w}\right)^{2}}{\left(1-S_{w}\right)\left(\mu_{r}-1\right)+1} \\
& \cdot\left[\mu_{r}\left(1-S_{w}\right)^{2}+4 S_{w}\left(1-S_{w}\right)\right. \\
& \left.+3 S_{w}^{2}\left(1-\frac{\left(\rho_{o}-\rho_{w}\right) g \sin (\theta)}{\frac{d P}{d x}-\rho_{o} g \sin (\theta)}\right)\right]
\end{aligned}
$$

where $\mu_{r}=\mu_{w} / \mu_{o}$ in Equations (71) and (72). It should be overemphasized here that the wetting tendency of the fracture walls plays no rule in two phase flow of water and heavy oil. In other words, the more viscous oil phase flows along the bottom wall, while water wets the top wall (Fig. 5). Therefore, these expressions are recommended for estimation of water and heavy oil relative permeabilities when the viscosity ratio is very small (e.g. $\mu_{r}<0.1$ ). Otherwise, Equations (67) to (70) should be used in water and typical oil two phase flow depending on different rock matrix wetting preferences.

\subsection{Viscosity Ratio}

Series of sensitivities were performed to investigate dependence of the relative permeability curves on the viscosity ratio in strongly water- and oil-wet systems (Figs. 6, 7). The data of Table 1 with different viscosity ratios are used in the analysis. According to these figures and functional form of Equations (67) to (70), the viscosity ratio of the flowing phases has substantial effect on the relative permeability curve of non-wetting phase and can lead to values much larger than unity, while it almost plays negligible rule in calculation of wetting phase relative permeability. In other words, values of the viscosity ratio less than unity give rise to water and oil relative permeabilities greater than unity in oil and water-wet systems, respectively (Figs. 6, 7).

Furthermore, the less the viscosity ratio, the more the nonwetting phase relative permeability exceeds unity. This unusual behavior respect to what is practically accepted, was previously observed by Pan [61] in experimental measurement of water-oil relative permeabilities in water-wet Hele-Shaw flow cell. They reported significant increase of oil (the non-wetting phase) relative permeability with its viscosity, but relative permeability curve of water (the wetting phase) wasn't affected by viscosity ratio very much. Additionally, they found that the relative permeability of oil (the non-wetting phase) could be as high as four at low water saturation in the water wet cell, while water (the wetting phase) relative permeability didn't exceed unity. This finding is in line with what is observed in this work. Pan [61] justified this behavior by lubrication effects because of flow of the water film(s) between the oil and the fracture wall(s) and its impacts on the flowing streams velocities. Indeed, when the less viscous phase is flowing along the fracture wall, the oil flow rate might be greater than that would result for single phase flow under the same condition.

Physically speaking, the meaning of the viscous coupling is that the velocity of each of the flowing streams is affected by the pressure gradient and viscosity of the adjacent streams, as well as its own pressure gradient and viscosity which would give rise to momentum transfer across the interfaces. This justification was adopted from the analyses of Dullien [62] about possibility of occurrence of lubrication phenomenon during multiphase flow in real porous media. It should be noted here that because of dominance of viscous forces for flow in fractures compared to matrix, much more significant effects of viscous coupling are expected for relative permeabilities through fractures.

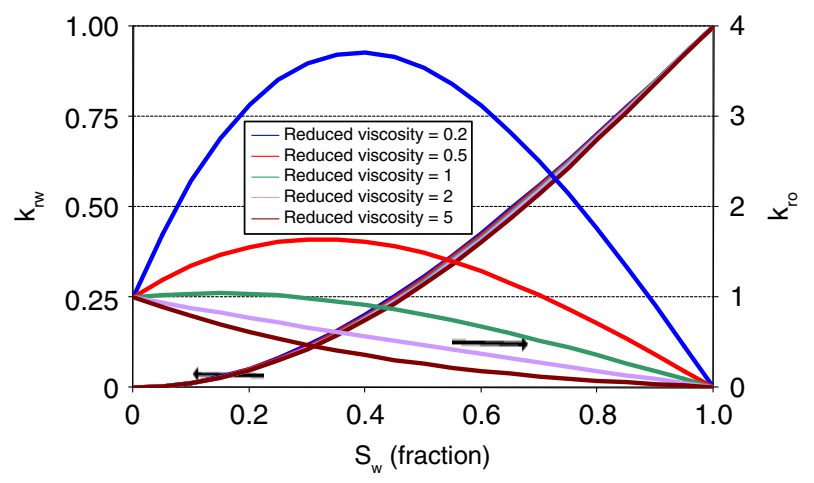

Figure 6

Effect of viscosity ratio on relative permeability curves for water-wet fracture walls.

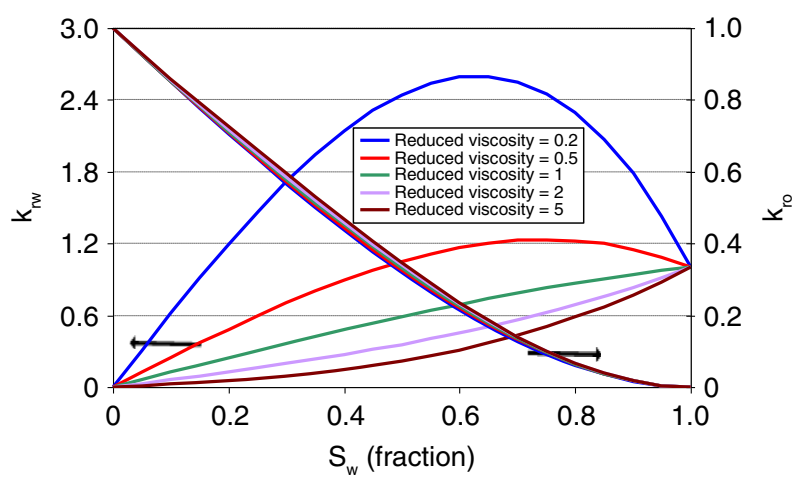

Figure 7

Effect of viscosity ratio on relative permeability curves for oil-wet fracture walls. 
In summary, the proposed analytical formulations demonstrate that relative permeabilities through fractures are functions of several rock and fluids properties including phase saturations, viscosity ratio, fluids density, inclination of fracture plate from the horizontal position, pressure gradient along fracture and rock matrix wettability. On the other hand, the newly developed relative permeability expressions are explicit functions of the parameters that are known for each of simulation computational cells or easy to measure in laboratory. It is also the first relative permeability model that takes the gravity terms into consideration. The other advantage of these formulations for applying in reservoir simulators is that it wouldn't require import of fracture relative permeabilities in tabular form. Therefore, these formulations are simple, efficient and accurate for implementation in dual-, multiple continuum and DFN commercial reservoir simulators.

\section{VALIDATION WITH EXPERIMENT}

Our extensive survey in the literature indicates that limited number of experimental works have been done to examine two phase flow in a single fracture. But, the majority of them used gas (nitrogen) and water in their experiments. On the other hand, among experimentally measured data of relative permeability curves in fractures only a few works have been done with oil and water as the flowing phases to be used for confirming the validity of the proposed formulations. Unfortunately, fracture orientation was horizontal in almost all of these experiments. Therefore, none of the existing relative permeabilities in the literature can be used to evaluate the validity of the gravity effects in the newly proposed model. Anyway, the validity of the proposed models is checked against the experimental data of Pan [61]. He measured oil and water relative permeabilities in a horizontally oriented cell of impermeable parallel fracture plates (the so-called Hele-Shaw cell). He developed three parallel-plates models which differ from each other in the injection method and experimental design. It was analyzed that the design of their third model can better mimic the basic physics of fluid flow in fractured reservoirs. It is because the fluids entered the fracture through a porous medium (sintered metal) instead of individual tubes in their first two models. This model was constructed with Plexiglas plates $38 \mathrm{~mm}$ thick. The adjustable aperture of the fracture could be changed from zero to $0.5 \mathrm{~mm}$. Three pairs of differential pressure transducers were installed on the bottom plate to measure the pressure gradient along the fracture. The plates were placed horizontally with a width and length of 100 and $550 \mathrm{~mm}$. The cells developed above analytical formulations are used to calculate the measured fracture relative permeabilities for water of viscosity $1.012 \mathrm{cp}$ and different oils (viscosities of 10.2, 66 and $106 \mathrm{cp}$ ) which correspond to viscosity ratios of $0.1,0.015,0.0096$, respectively. The fracture average apertures in these tests were 106, 112 and $125 \mu \mathrm{m}$. Meanwhile, the range of the pressure gradients along the fractures were $16-130,5-932$ and $25-462 \mathrm{kPa} / \mathrm{m}$ for the viscosity ratio of $0.1,0.015,0.0096$, respectively.

Figures 8,9 and 10 show comparison between the calculated and measured relative permeabilities. Clearly, good agreement is found between them. Therefore, using the newly developed functions is sufficient to match the experimental data. In order to further validate the developed analytical models, the useful intermediate data of the above experiments are used to numerically extract the relative permeabilities. A nonlinear history-matching is performed for numerical derivation of the relative permeabilities. A commercial reservoir simulator is coupled with a

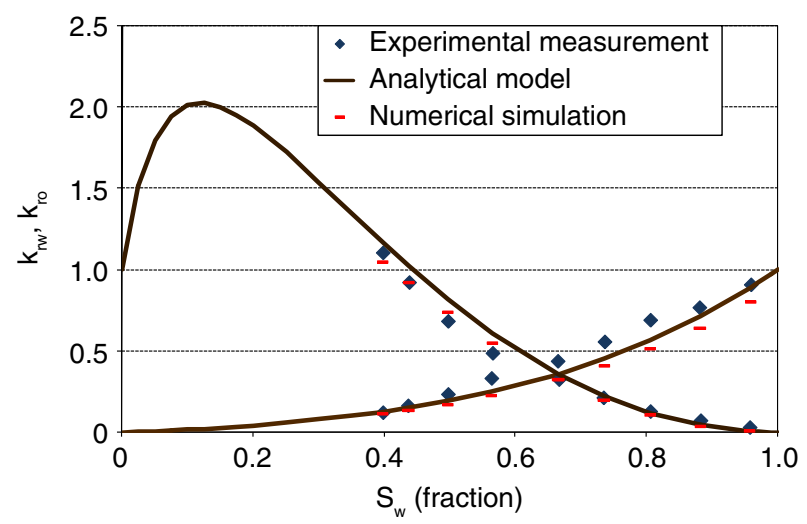

Figure 8

Comparison of calculation of the analytical model with experimental measurement of Pan (1999) [61] for $\mu_{r}=0.1$.

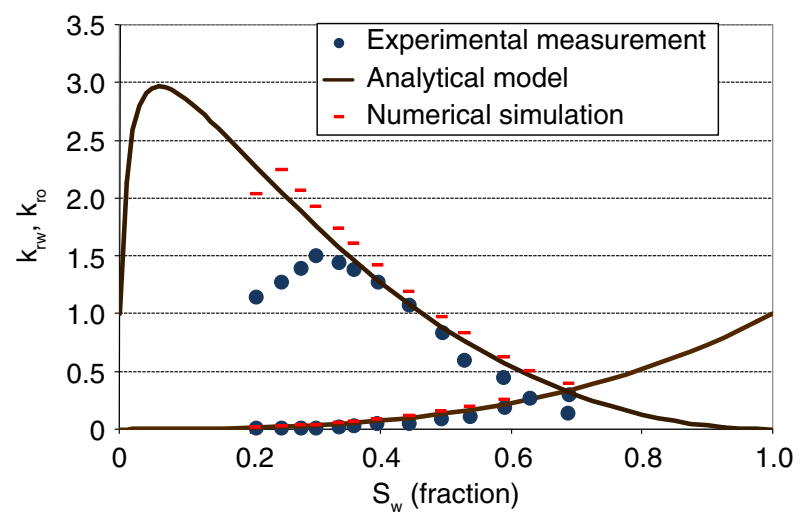

Figure 9

Comparison of calculation of the analytical model with experimental measurement of Pan (1999) [61] for $\mu_{r}=0.015$. 


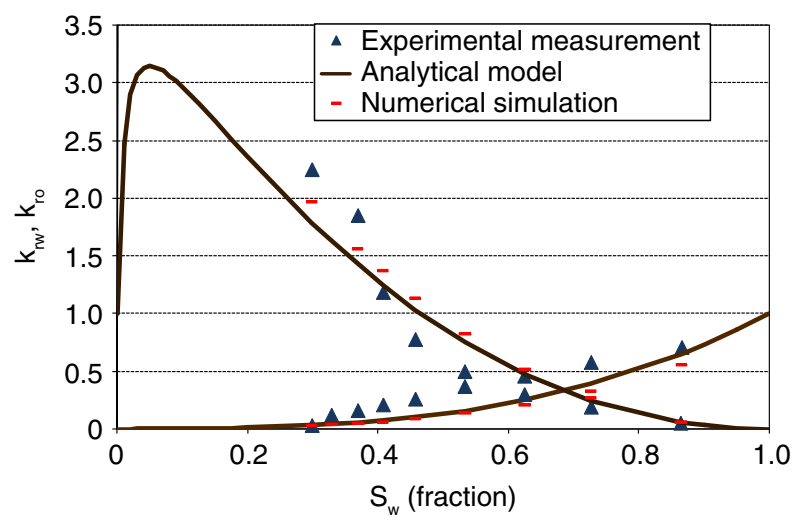

Figure 10

Comparison of calculation of the analytical model with experimental measurement of Pan (1999) [61] for $\mu_{r}=0.0096$.

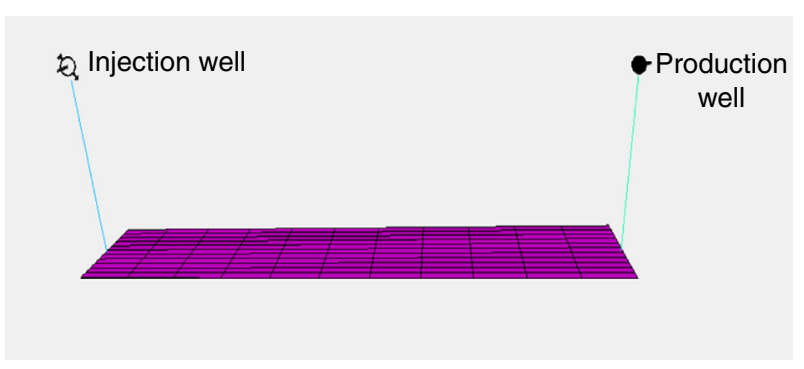

Figure 11

Gridding of the fracture for numerical validation of the analytical relative permeabilities.

MATLAB-based optimization code to minimize the following objective function:

$$
\sum_{i=1}^{N}\left(\left(\frac{d P}{d x}\right)_{i}^{\text {experiment }}-\left(\frac{d P}{d x}\right)_{i}^{\text {simulation model }}\right)^{2}
$$

where $\left(\frac{d P}{d x}\right)_{i}$ are pressure gradients for injection of the fluids with different flow rate ratios and $N$ is the number of experiments with different injection rates for a fixed set of fracture and fluid properties. In order to prevent numerical dispersion, the fractures are subdivided into many grid cells and single porosity fine grid simulations are performed (Fig. 11). Grid cells porosity was set equal to unity and absolute permeabilities are calculated from Equation (1). The linear relative permeabilities are used as the initial guess and capillary forces are neglected for flow in the fractures. The model is initiated with water filled fracture grid cells. Figure 12 compares the experimental measurements of

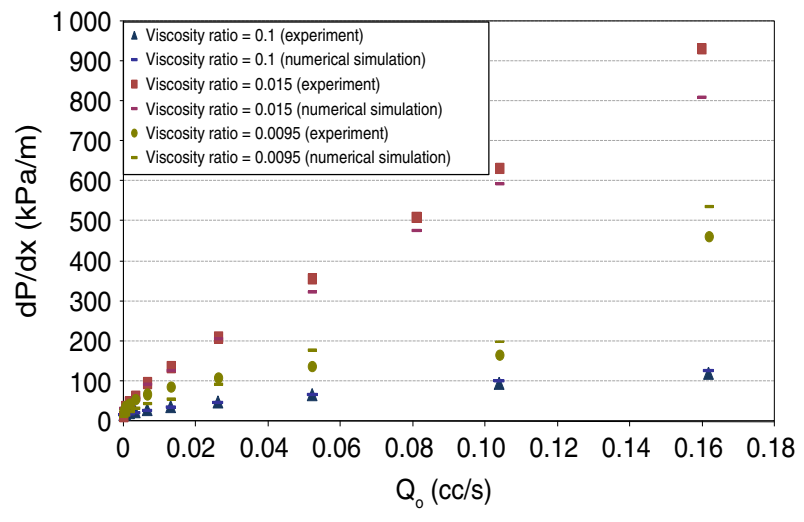

Figure 12

Experimental pressure gradient data compared with results of the numerical simulator.

pressure gradient with numerically estimated values for the three experiments described above. The slight deviation of the numerical calculation of pressure gradient from the experimental measurement, particularly at the high flow rates can be attributed to the possible deflection of the fracture walls at high pressure gradients. The satisfactory matches between the analytical, numerical and experimentally-derived relative permeabilities in Figures 8, 9 and 10 guarantee validity of the newly developed formulations for accurate calculation of relative permeabilities of water and oil through fractures.

Unfortunately, due to lack of the experimental measurement of relative permeabilities in non-horizontal fractures it wasn't possible to evaluate the validity of the gravity effects in the newly proposed model. Therefore, it is highly recommended that the future experimental researches are conducted in inclined fractures. This will surely provide valuable experimental data to validate the analytical prediction of the gravity effects contribution in multiphase flow through fractures.

\section{EVALUATION OF THE ASSUMPTIONS}

Two main assumptions that were made in the development of the mathematical model of this article include laminar and stratified flow in fractures. These assumptions are examined here.

Laminar flow in fractures. It is evident that laminar flow assumption is reasonable for the ranges of the velocity usually occur in the bulk of reservoirs $(1 \mathrm{ft} /$ day $\sim 31 \mathrm{~cm} /$ day $)$.

Segregated stratified flow pattern: this assumption is equivalent to large viscous and gravity forces compared to capillary force in fractures. Capillary pressure for flow 
TABLE 2

Fracture capillary pressure as a function of aperture for water-oil system

\begin{tabular}{|c|c|}
\hline Fracture aperture $(\mu \mathrm{m})$ & Capillary pressure $(\mathrm{kPa})$ \\
\hline 1 & 80 \\
\hline 10 & 8 \\
\hline 50 & 1.6 \\
\hline 100 & 0.8 \\
\hline 200 & 0.4 \\
\hline 300 & 0.27 \\
\hline 400 & 0.2 \\
\hline 500 & 0.16 \\
\hline 600 & 0.13 \\
\hline 700 & 0.11 \\
\hline 800 & 0.099 \\
\hline 900 & 0.089 \\
\hline 1000 & 0.08 \\
\hline 6000 & 0.013 \\
\hline
\end{tabular}

between two flat parallel plates can be calculated by the following equation:

$$
P_{c}=\frac{2 \sigma \cos (\theta)}{b}
$$

where $\sigma$ is interfacial tension between fluids, $\theta$ is contact angle and $b$ is fracture aperture. This equation was used by Wang and Narasimhan [63] to study fluid flow in partially saturated fractured porous media. The usefulness of Equation (74) can be utilized to show the dependence of fracture capillary pressure on its aperture. According to this equation, capillary forces are weaker in wider fractures and stronger in narrower ones. For typical water-oil systems, we assume that $\sigma=0.04 \mathrm{~N} / \mathrm{m}$ and $\theta=0$. For these values, fractures capillary pressure as a function of aperture is given in Table 2 and shown in Figure 13. In order to judge about the assumption of dominance of viscous and gravity forces to capillary force in a single fracture using Figure 13, it is essential to answer one important question: how wide are natural fractures? Several researchers [64-71] reported observation of fracture apertures ranging from about 30 to over $6000 \mu \mathrm{m}$. These researchers stated that the apertures in the range of 50 to $200 \mu \mathrm{m}$ seem to be very common, while $6000 \mu \mathrm{m}$ fracture apertures were rarely observed. However, Weber and Bakker [72] stated that the size of fracture aperture can be enlarged by leaching as much

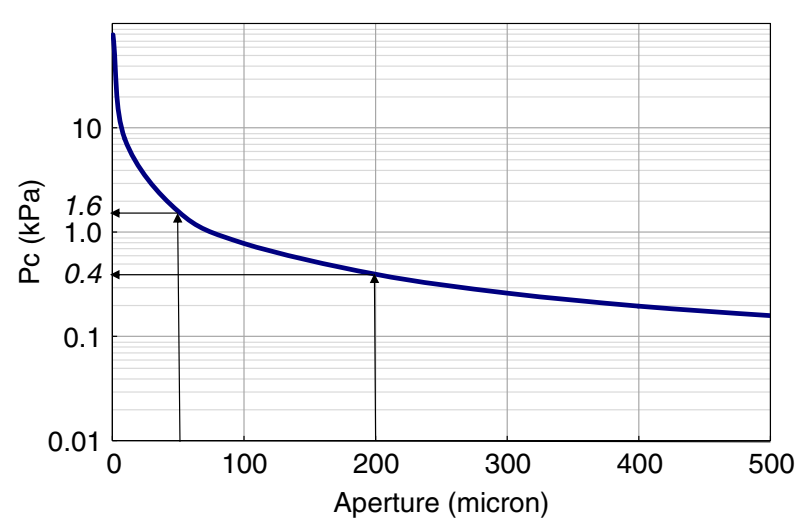

Figure 13

Fracture capillary pressure as a function of aperture for wateroil system.

as $5000 \mu \mathrm{m}$. Therefore, the typical range of observed fracture apertures in field experiences around the world is 50-200 $\mu \mathrm{m}$. This range is equivalent to capillary pressure range of 1.6-0.4 $\mathrm{kPa}$. Thus, capillary forces are much weaker in fractures than in matrix blocks. Recently, Noroozi et al. [73] performed full field simulation on an Iranian reservoir to show effect of fractures capillary pressure on history matching. Their simulation study concluded that fractures capillary pressure can be considered zero in water-oil system.

It is worth noting that fracture walls were assumed to be strongly water wet by considering contact angle equal to zero in the above computations. In carbonate reservoirs with oil wetness tendency, fractures capillary pressure is several times less than the values of Table 2 and Figure 13. Since fractures are usually observed in dense and brittle reservoirs with high capillary pressures of tens of pounds per square inch, it can be neglected in fractures compared to matrix blocks. Furthermore, if the assumption was unrealistic, the good agreements between the calculated relative permeabilities using the new formulations and measured data wouldn't be observed.

\section{CONCLUSIONS}

The following conclusions can be drawn from this work:

- although, several formulations are available to calculate fracture relative permeability curves in the form of linear and power functions of saturations, the classic Romm's $X$-type curves are still used in almost all of the reservoir simulators;

- the basic fluid flow equations were combined the above formulations to propose new simple analytical formulations for two phase relative permeabilities through 
fractures. The newly developed relative permeability expressions are explicit functions of phase saturations, viscosity ratio, fluids density, inclination of fracture from the horizon, pressure gradient along fracture and rock matrix wettability. It is also the first relative permeability model that takes the gravity effects and fracture wall wettability into consideration;

- good agreements of calculations of the model with literature experimental data verify the validity of the analytical formulations;

- it was explicitly shown that viscosity the ratio has substantial effect on the relative permeability curve of nonwetting phase and can lead to values greater than unity, while it almost plays no rule in calculation of wetting phase relative permeability. This unusual behavior respect to what is practically accepted was observed in experimental measurement of water-oil relative permeabilities. We justified such observation by the lubrication and viscous coupling effects for multiphase flow in fractures;

- the main advantage of these formulations for applying in commercial reservoir simulators is that it would not require the import of fracture relative permeabilities in tabular form. Therefore, these formulations are simple, efficient and accurate for implementation in dual-, multiple continuum and DFN reservoir simulators.

\section{ACKNOWLEDGMENTS}

The author would like to thank National Iranian Oil Company (NIOC) and National Iranian South Oil Company (NISOC) for their help.

\section{REFERENCES}

1 Ahmed T. (2010) Reservoir Engineering Handbook, 4th edn, Gulf Professional Publishing.

2 Bourbiaux B., Fourno A., Nguyen Q.L., Norrant F., Robin M., Rosenberg E., Argillier J.F. (2014) Experimental and Numerical Assessment of Chemical EOR in Oil-wet NaturallyFractured Reservoirs, SPE Improved Oil Recovery Symposium, Tulsa, Oklahoma, USA, April 12-16, SPE Paper 169140.

3 Ramirez B., Kazemi H., Al-Kobaisi M., Ozkan E., Atan S. (2009) A Critical Review for Proper Use of Water/Oil/Gas Transfer Functions in Dual-Porosity Naturally Fractured Reservoirs: Part I, SPE Res. Eval. Eng. 12, 2, 200-210.

4 Gilman J.R. (2003) Practical aspects of simulation of fractured reservoirs, International forum on reservoir simulation, Buhl, Baden-Baden, Germany.

5 Saidi A.M. (1983) Simulation of Naturally fractured Reservoirs, SPE Reservoir Simulation Symposium, San Francisco, CA, 15-18 Nov, SPE 12270.

6 Fung L.S.K. (1991) Simulation of Block-to-Block Processes in Naturally fractured Reservoirs, SPE Res. Eval. Eng. 6, 4, 477-484.
7 Uleberg K., Kleppe J. (1996) Dual Porosity, Dual Permeability Formulation for Fractured Reservoir Simulation, Norwegian University of Science and Technology, Trondheim RUTH Seminar, Stavanger.

8 Kazemi H., Gilman J.R. (1993) Multiphase Flow in Fractured Petroleum Reservoirs, in Flow and Contaminant Transport in Fractured Rock, Bear J., Tsang C.F., de Marsily G. (eds), San Diego, California, Academic Press, pp. 267-323.

9 Al-Kandari H.A., Kazemi H., Van Kirk C.W. (2002) Gas Injection Enhanced Oil Recovery in High Relief Naturally Fractured Reservoirs, Kuwait University Technical Conference and Exhibition, November.

10 Liu H., Di Donato G., Blunt M.J. (2006) General Transfer Functions for Multiphase Flow, SPE Annual Technical Conference and Exhibition, San Antonio, TX, 24-27 Sept., Paper SPE 102542.

11 Saboorian-Jooybari H., Ashoori S., Mowazi G. (2012) Development of an Analytical Time-Dependent Matrix/ Fracture Shape Factor for Countercurrent Imbibition in Simulation of Fractured Reservoirs, Transp. Porous Media 92, 3, 687-708.

12 Saboorian-Jooybari H., Khademi N. (2014) Traveling Wave Analysis of Cocurrent Imbibition in Porous Media, Journal of Porous Media 17, 3, 185-195.

13 Barenblatt G.I., Zheltov I.P., Kochina I.N. (1960) Basic concepts in the theory of seepage of homogeneous liquids in fissured rocks, PMM. Sov. Appl. Math. Mech. 24, 5, 852-864.

14 Warren J.E., Root P.J. (1963) The behavior of naturally fractured reservoirs, SPE J. 245-255.

15 Kazemi H. (1990) Naturally fractured reservoirs, 3rd International Forum on Reservoir Simulation, Baden, Austria.

16 Pruess K., Narasimhan T.N. (1985) A practical method for modeling fluid and heat flow in fractured porous media, SPE J. 25, 14-26.

17 Stothoff S., Or D. (2000) A discrete-fracture boundary integral approach to simulating coupled energy and moisture transport in a fractured porous medium, in Dynamics of Fluids in Fractured Rocks, Concepts and Recent Advances, Faybishenko B., Witherspoon P.A., Benson S.M. (eds), AGU Geophysical Monograph 122, American Geophysical Union, Washington, DC, pp. 269-279.

18 Collins F. (1988) Evaluation of the improved dual-porosity model for the simulation of gravity effects in naturally fractured reservoirs, 39th Ann. Tech. Meeting of the Petroleum Society of Canadian Institute of Mining, Calgary, Canada, CIM paper No. 88-39-05.

19 Bourbiaux B. (2010) Fractured Reservoir Simulation: a Challenging and Rewarding Issue, Oil \& Gas Science and Technology - Rev. IFP 65, 2, 227-238.

20 Lemonnier P., Bourbiaux B. (2010) Simulation of Naturally Fractured Reservoirs State of the Art - Part 1 - Physical Mechanisms and Simulator Formulation, Oil \& Gas Science and Technology - Rev. IFP 65, 2, 239-262.

21 Lemonnier P., Bourbiaux B. (2010) Simulation of Naturally Fractured Reservoirs. State of the Art - Part 2 - Matrix-Fracture Transfers and Typical Features of Numerical Studies, Oil \& Gas Science and Technology - Rev. IFP 65, 2, 263-286.

22 Henn N., Quintard M., Bourbiaux B., Sakthikumar S. (2004) Modelling of Conductive Faults with a Multiscale Approach, Oil \& Gas Science and Technology - Rev. IFP 59, 2, 197-214. 
23 Johnson E.F., Bossler D.P., Naumann V.O. (1959) Calculation of relative permeability from displacement experiments, Trans. AIME 216, 370

24 Saraf D.N., McCaffery F.G. (1982) Two- and Three-Phase Relative Permeabilities: a Review, Petroleum Recovery Institute Report \#81-8, Calgary, Alberta, Canada.

25 Jones S.C., Roszelle W.O. (1978) Graphical techniques for determining relative permeability from displacement experiments, J. Pet. Technol. 5, 807.

26 Sarem A.M. (1959) Significance of water-oil relative permeability data calculated from displacement tests, Conference of Theory of Fluid Flow in Porous Media, University of Oklahoma, Norman, 189.

27 Archer J.S., Wong S.W. (1973) Use of a reservoir simulator to interpret laboratory waterflood data, SPE Journal 13, 343-347.

28 Honarpour M., Koederitz L., Harvey H. (1986) Relative Permeability of Petroleum Reservoirs, Boca Raton, FL, CRC Press.

29 Honarpour M., Mahmood S.M. (1988) Relative-permeability measurements-an overview, Journal of Petroleum Technology 40, 963-966.

30 Lomize G.M. (1951) Flow in Fractured Rocks (in Russian), Gosenergoizdat, Moscow 127 pp.

31 Snow D.T. (1965) Anisotropic permeability of fractured media, Water Resour. Res. 5, 6, 1273-1289.

32 Louis C.A. (1969) A study of groundwater flow in jointed rock and its influence on the stability of rock masses, Rock Mech. Res. Rep. 10, Imperial College, London, 90 pp.

33 Bear J. (1972) Dynamics of Fluids in Porous Media, Elsevier, New York, p. 764.

34 Witherspoon P.A., Wang J.S.Y., Iwai K., Gale J.E. (1980) Validity of cubic law for fluid flow in deformable rock fracture, Water Resour. Res. 16, 6, 1016-1024.

35 Romm E.S. (1966) Fluid Flow in Fractured Rocks (in Russian), Nedra Publishing House, Moscow.

36 Van Golf-Racht T. (1982) Fundamentals of Fractured Reservoir Engineering, Elsevier Scientific, New York.

37 Thomas L.K., Dixon T.N., Pierson R.G. (1983) Fractured reservoir simulation, SPE J. 23, 1, 42-54.

38 Gilman J.R., Kazemi H. (1983) Improvements in simulation of naturally fractured reservoirs, SPE J. 23, 4, 695-707.

39 Kazemi H., Gilman J.R. (1989) Multiphase flow in fractured petroleum reservoirs, Advanced Workshop on Heat and Mass Transport in Fractured Rocks, Lab. Nac. Eng. Civ. (LNEC), Lisbon, June.

40 Grant M.A. (1977) Permeability reduction factors at Wairakei, AIChE-ASME Heat Transfer Conference, Am. Inst. of Chem. Eng. and Am. Soc. of Mech. Eng., Salt Lake City, Utah.

41 Pruess K., Bodvarsson G.S., Stefansson V., Eliasson E.T. (1984) The Krafla geothermal field, Iceland, 4, History match and prediction of individual well performance, Water Resour. Res. 20, 11, 1561-1584.

42 Merrill L.S. (1975) Two phase flow in fractures, PhD Thesis, University of Denver.

43 Pruess K., Tsang Y.W. (1990) On two-phase relative permeability and capillary pressure of rough-walled rock fractures, Water Resour. Res. 26, 9, 1915-1926.
44 Rossen W.R., Kumar A.T.A. (1992) Single- and two-phase flow in natural fractures, 67th Annual Technical Conference of the Society of Petroleum Engineers, Washington, DC, 4-7 Oct., SPE Paper 24195.

45 Persoff P.K., Pruess K., Myer L. (1991) Two-Phase Flow Visualization and Relative Permeability Measurement in Transparent Replicas of Rough-Walled Rock Fractures, 16th Workshop on Geothermal Reservoir Engineering, Stanford, California, 23-25 Jan.

46 Persoff P., Pruess K. (1995) Two-Phase Flow Visualization and Relative Permeability Measurement in Natural Rough-Walled Rock Fractures, Water Resources Research 31, 5, 1175-1186.

47 Fourar M., Bories S., Lenormand R., Persoff P. (1993) TwoPhase Flow in Smooth and Rough Fractures: Measurement and Correlation by Porous-Medium and Pipe Flow Models, Water Resources Research 29, 11, 3699-3708.

48 Fourar M., Bories S. (1995) Experimental Study of Air-Water Two-Phase Flow through a Fracture (Narrow Channel), Int. J. Multiphase Flow 21, 4, 621-637.

49 Pan X., Wong R.C., Maini B.B. (1996) Steady State Two-Phase Flow in a Smooth Parallel Fracture, Presented at the 47th Annual Technical Meeting of the Petroleum Society in Calgary, Alberta, Canada, June 10-12.

50 Rangel-German E., Akin S., Castanier L. (1999) MultiphaseFlow Properties of Fractured Porous Media, SPE Western Regional Meeting, Anchorage, AK, SPE Paper 54591.

51 Pieters D.A., Graves R.M. (1994) Fracture Relative Permeability: Linear or Non-Linear Function of Saturation, SPE International Petroleum Conference \& Exhibition of Mexico, Veracruz, Mexico, 10-13 Oct, SPE Paper 28701.

52 Horne R.H., Satik C., Mahiya G., Li K., Ambusso W., Tovar R., Wang C., Nassori H. (2000) Steam-Water Relative Permeability, World Geothermal Congress, Kyushu-Tohoku, Japan, 28 May - 10 June.

53 Diomampo G.P. (2001) Relative Permeability Through Fractures, Report SGP-TR-170 prepared under DOE contract No. DE-FG07-95ID13370, August.

54 Chen A. (2005) Liquid-Gas Relative Pemeabilities in Fractures: Effects of Flow Structures, Phase Transformation and Surface Roughness, PhD Thesis, Stanford University.

55 Corey A.T. (1954) The interrelationship between gas and oil relative permeabilities, Prod. Mon. 19, 38-41.

56 Fourar M., de Nancy E., Lenormand R. (1998) A Viscous Coupling Model for Relative Permeabilities in Fractures, SPE Annual Technical Conference and Exhibition, New Orleans, LA, USA, SPE Paper 49006.

57 Shad S., Gates I.D. (2010) Multiphase Flow in Fractures: Cocurrent and Counter-Current Flow in a Fracture, Journal of Canadian Petroleum Technology 49, 2, 48-55.

58 Brown S.R., Scholz C.H. (1985) Broad Bandwidth Study of the Topography of Natural Rock Surfaces, J. Geophys. Res. 90, 12575-12582.

59 Toledo P.G., Nvoy A.R., Davis H.T. (1990) Hydraulic Conductivity of Porous Media at Low Water Content, Soil Science of America J. 54, 3, 673.

60 Streeter V.L., Wylie E.B., Bedford K.W. (1997) Fluid Mechanics, 9th edn, McGraw-Hill publishing company.

61 Pan X. (1999) Immiscible Two-Phase Flow in a Fracture, $P h D$ Thesis, University of Calgary, Calgary, Alberta, Canada. 
62 Dullien A.L. (1993) Physical interpretation of hydrodynamic coupling in a steady-state two phase flow, 13th Annual Hydrology Meeting of American Geophysical Union, Colorado State University, Fort Collins, Colorado, pp. 363-377.

63 Wang J.S.Y., Narasimhan T.N. (1985) Hydrologic Mechanisms Governing Fluid Flow in a Partially Saturated, Fractured, Porous Medium, Water Resource Research 21, 12, 1861-1874.

64 Banward S.E., Gustafsson M., Laaksoharju E.L.T., Wallin B. (1994) Large Scale intrusion of shallow water into a vertical fracture zone in crystalline bedrock: Initial hydrochemical perturbation during tunnel construction at the Äspö Hard Rock Laboratory, southeastern Sweden, Water Resources Research 30, 6, 1747-1763.

65 Folger P.F., Poeter E., Wanty R.B., Frishman D., Day W. (1996) Controls on $222 \mathrm{Rn}$ variations in a fractured crystalline rock aquifer evaluated using aquifer tests and geophysical logging, Groundwater 34, 2, 250-261.

66 Himmelsbach T., Hbtzl H., Maloszewski P. (1998) Solute Transport Processes in a Highly Permeable Fault Zone of Lindau Fractured Rock Test Site (Germany), Groundwater 36, 5, 792-800.

67 Kumar A.T.A., Majors P.D., Rossen W.R. (1997) Measurement of Aperture and Multiphase Flow in Fractures using NMR Imaging, SPE Formation Evaluation 12, 2, 101-108.
68 Schrauf T.W., Evans D.D. (1986) Laboratory Studies of Gas Flow through a Single Natural Fracture, Water Resources Research 22, 7, 1038-1050.

69 Shapiro A.M., Nicholas J.R. (1989) Assessing the validity of the channel model of fracture aperture under field conditions, Water Resources Research 25, 5, 817-828.

70 Novakowski K.S., Lapcevic P.A. (1994) Field measurement of radial solute transport in fractured rock, Water Resources Research 30, 1, 37-44.

71 Hensel W. (1987) A Perspective Look at Fracture Porosity, 62nd Annual Technical Conference and Exhibition of the Society of Petroleum Engineers, Dallas, TX, 27-30 Sept., SPE Paper 16806.

72 Weber K.J., Bakker M. (1981) Fracture and Vuggy Porosity, SPE Annual Technical Conference and Exhibition, 4-7 Oct., San Antonio, Texas, Paper SPE 10332

73 Noroozi M.M., Moradi B., Bashiri G. (2010) Effects of Fracture Properties on Numerical Simulation of a Naturally Fractured Reservoir, Trinidad and Tobago Energy Resources Conference, Port of Spain, Trinidad, 27-30 June, SPE Paper 132838.

Manuscript submitted in August 2013 Manuscript accepted in November 2014 Published online in April 2015

Cite this article as: H. Saboorian-Jooybari (2016). Analytical Estimation of Water-Oil Relative Permeabilities through Fractures, Oil Gas Sci. Technol 71, 31. 